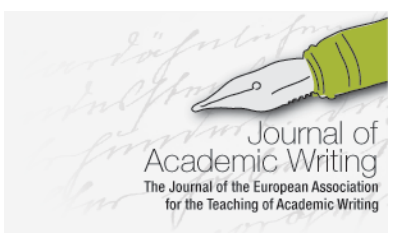

Journal of Academic Writing

Vol. 10 No 1 WINTER 2020, pages 25-42

https://doi.org/10.18552/joaw.v10i1.592

\title{
Video Tutorials as Academic Writing and Research Support for Students of International Business
}

\author{
Larssyn Staley \\ University of Applied Sciences and Arts, Northwestern Switzerland, Switzerland \\ Susan Göldi \\ University of Applied Sciences and Arts, Northwestern Switzerland, Switzerland \\ Anna Nikoulina \\ University of Applied Sciences and Arts, Northwestern Switzerland, Switzerland
}

\begin{abstract}
Many studies have made claims for the positive effects of multimedia in education; however, there is a lack of systematic and comparable research, especially when it comes to video tutorials. This study evaluates the use and benefits of short screencast video tutorials, produced with Camtasia and published on YouTube, in preparing students for research-based writing assignments. The study employs a multi-method research design, comprising an analysis of video-tutorial viewership data from YouTube and a student questionnaire on the perceived benefits of these video tutorials. The data on how the tutorials are used, as well as the questionnaire responses, enable us to highlight which aspects of these tutorials positively affect the learning process. Findings indicate that the use of such tutorials is more dependent on the type of information included (e.g., theory, instructions or examples), than their length (within the range of 3-6 min). Additionally, novice, introductory-level students appear to have received greater benefit from the tutorials than students with some previous academic writing experience.
\end{abstract}

\section{Introduction}

The use of multimedia, especially educational videos, has become an essential part of learning in higher education settings. Podcasts, video lectures, and video tutorials are implemented in a range of pedagogical settings and are widely researched in tertiary education and outside academia. Video tutorials are used in a range of subject fields, such as chemistry (He et al., 2012), medicine (Balslev et al., 2005; Stefanidis et al., 2007; Carson \& Wilcox, 2019), and business and economics (Fulton \& Fulton, 2018). The use of video tutorials is also commonplace in libraries (Weeks \& Davis, 2017; Tewell, 2010), for example, teaching students about plagiarism (Thornton \& Kaya, 2013). Video tutorials have also been used to teach academic writing and research skills (Engin, 2014; Bourdeau et al., 2017).

Several studies have made claims for the positive effects of using multimedia in education. For example, video tutorials have the potential to positively affect learning effectiveness (Bourdeau et al., 2017). Wells et al. (2012) also link well-designed and readily available video tutorials with student satisfaction and better performance, as video tutorials "encourage students to learn how they want, when they want and at a pace that suits their needs" (p. 453). However, research on video tutorials in higher education remains inconclusive, as the object of discussion, for example, length, style, and content of the videos, varies from one study to the next. Therefore, the positive effects found by one and the adverse effects by another are not 
necessarily contradictory, but instead represent different parts of the bigger picture. The need for more research on the effectiveness of video tutorials has already been underscored (Bowles-Terry et al., 2010). We aim to add to the growing body of research on this topic.

In this paper, we contribute to this discussion by taking a mixed-method approach with the aim of better understanding the role of short screencast video tutorials, specifically in preparing students for research-based writing assignments. We rely on students' self-reported perception of the usefulness of these video tutorials and on viewership data that indicate the number of views, viewers scrolling, and discontinued viewership. Although self-reported data have been criticised for various weaknesses, such as respondents' lack of ability to report accurately or social-desirability biases (Fredricks \& McColskey, 2012), their benefits should not be discounted. Self-reported data, such as questionnaires, are particularly helpful when researching perceived benefits and intellectual engagement, which are not always directly observable (Appleton et al., 2006; Fredricks \& McColskey, 2012).

A student questionnaire was used to elicit the students' ( $n=76)$ perceived benefits of videotutorial use, such as tips, guidance, confirmation, motivation or confidence. These data enable us to highlight which aspects of these tutorials potentially affect the learning process, and importantly, how the detected aspects can be shaped in order to provide support for academic writing students. The viewership data were collected from YouTube Studio $(n=350$ views August-November 2019). They offer an observable measure of viewership to complement the self-reports on perceived engagement and provide further information on use.

In the following pages, we outline relevant aspects of multimedia and cognitive learning theories, the effects of multimedia use on the learning process, and recommendations and precautions from previous research on using video tutorials to support the learning process. We then present our data and link it, where possible, to theoretical concepts and results from previous studies.

\section{Theoretical Framework}

The effects of multimedia on the learning process, specifically video tutorials, have been the subject of much research (Korkut et al., 2015). Research points out that video tutorials can enhance learning because they draw on multiple mediums, such as words and pictures, to reach an audience. According to multimedia learning theory, learning is enhanced by multimedia because the human information-processing system contains auditory/verbal and visual/pictorial channels. As a result, learners can better understand an explanation when presented in words and pictures than when presented in words alone (Mayer, 2001; Watzlawick et al., 1967). Mayer (2005) provides additional support as "people learn more deeply from words and pictures than from words alone" (p. 31). Cognitive load theory helps shed light on the effects of multimedia on the learning process. Due to the modality effect, which is central to cognitive load theory, "learning is more efficient when a text referring to a map, graph, diagram, or tabular information is presented orally than visually" (Puma \& Tricot, 2019, p. 1200; see also Paas \& Ayres, 2014). In other words, learning from a visual and written explanation is less effective than learning from the same visualisation with a comparable audio description (Castro-Alonso \& Sweller, 2019), provided that the auditory and visual information support each other (Göldi \& Künzi, 2017).

Further research adds evidence for the usefulness of video tutorials in educational settings. For example, Galster et al. (2018) found video tutorials to be a powerful tool for studying. They simulate the in-class learning experience and are useful for short introductions and summaries (Ganesan, 2018). Video tutorials have been shown to enable students to review materials, thus augmenting and clarifying the material covered in class (Morton \& Colbert-Getz, 2017; Puma et al., 2018). Mestre (2012) and Alekseiva-Petrova et al. (2019) found that students appreciate video tutorials as they make instruction more flexible and interactive. Students can learn at their own pace (Henderson et al., 2017; Hsiao et al., 2017; Käfer et al., 2017; Sachs et al., 2013; Worlitz et al., 2018). Moreover, when comparing four different instructional designs, Meij and Meij (2014) found that students are better at task completion under conditions including video 
tutorials than students who only received paper-based instruction. The use of video tutorials is also said to support the acquisition of more advanced competencies, such as problem solving and analysis (Morton \& Colbert-Getz, 2017). Hogarth and Luke (2010) and Tsai (2019) found video tutorials help students become more autonomous learners, specifically in flippedclassroom settings.

DeVaney (2009) examined students' attitudes towards video tutorials used as a supplement to written instruction. Students' perception of video tutorials was mainly positive. Using focus groups and interviews to assess students' needs, Bussell et al. (2017) found a connection between student maturity and appreciation for learning material offered on demand; more advanced learners (doctoral students) showed more confidence and less demand for video tutorials. On a more theoretical level, Kalyuga (2007) also found that instructional guidance, via video tutorials, is more beneficial for novices than advanced learners.

Previous research on the use of educational video tutorials provides several valuable recommendations about how to conceptualise and structure video tutorials for the best results. This body of research covers goals, length, design, and accessibility. Although learning goals are essential for all types of instruction (Göldi, 2011), Weeks and Davis (2017) and McGuinness and Futon (2019) state that learning goals are pivotal for planning and creating useful video tutorials.

Bowles-Terry et al. (2010) posited that the effectiveness of videos as a means of instruction is directly dependent on the length of the video. Furthermore, more recent research indicates that students prefer to watch short videos or "smaller chunks" of video content at a time (Martin \& Martin, 2015, p. 48). Bowles-Terry et al. (2010) assert that video tutorials should be shorter than $3 \mathrm{~min}$. This assertion is somewhat supported by Chen and Yang (2019), who find that engagement with content extends to $6 \mathrm{~min}$ but is highest when the video is less than $3 \mathrm{~min}$. In contrast, Guo et al. (2014) found that students stay engaged even during longer videos, between 6-12 min, whereas Martin and Martin (2015) found that, regardless of its length or presence or absence of an introduction, only about a third of the viewers complete a whole video. What must be underscored is that the type of video and the tutorial content vary between these studies, so it is not necessarily the case that these results are contradictory, but rather that the focus is inconsistent. This inconsistency further underscores the need for a more indepth and broader range of research on the topic. Despite the variance in the video type and design being researched, the overall consensus is that shorter videos provide a more precise focus (Guo et al., 2014; Martin \& Martin, 2015; Weeks \& Davis, 2017).

In addition to length, style influences the perceived usefulness of video tutorials. For example, Mestre (2012, p. 101) suggests that effective video tutorials should "blend learning with fun". He advises educators to combine screencast, video and animation to enable students to read, watch, and have fun with content at the same time. However, Buchner (2018, p. 7) advises against using "Hollywood-Style" video tutorials, and Bowles-Terry et al. (2010, p. 13) support this recommendation. They argue that educators should not waste any "time and resources creating elaborate or entertaining video tutorials" as students do not expect video tutorials to be "flashy" or "fancy". However, Ljubojevic et al. (2014) claim that videos with high entertainment content can be useful for engaging and motivating students; they are not as efficient as purely educational videos in achieving a learning outcome. Brame (2016) makes several recommendations for the development of educational videos, such as using on-screen text or symbols to highlight important information, segmenting, or chunking information to allow learners to engage with small pieces of new information, as well as giving them control over the flow of further information. As mentioned above, the media have to support each other to convey a coherent message (e.g., the use of an audio/verbal channel and the visual/pictorial channel to communicate new information must coincide). In support of this, Evmenova et al. (2011) find that video tutorials with captions are more effective than those without. Moreover, extraneous information should be excluded from the video to focus on the essential content (Brame, 2016; Weeks \& Davis, 2017).

Accessibility of video tutorials is also an important factor for students. Bowles-Terry et al. (2010, p. 15) state that video tutorials should be accessible at the "point of need" as students do not 
actively seek them. Martin and Martin (2015) suggest publishing videos on YouTube since it is a familiar medium to students, free and searchable, and in 2020 had 2 billion users (Statista, 2020), making it the most popular social media site in Switzerland (Plaga et al., 2019). Furthermore, easy access is essential and additional promotion may also be needed (Weeks \& Davis, 2017).

Multimedia forms of instruction can add educational value. They can support the cognitive process of learning and can be used outside the classroom to promote autonomous learning. However, when reviewing previous studies, it becomes clear that the cause-and-effect relationship of video tutorial design, use and educational benefit is complex. The current ability to draw definite conclusions about which factors speak for or against the use and benefits of video tutorials is limited. Although a range of studies exists, the video-design, research design and research context vary among the studies. Many previous studies are highly context specific in that the subjects of the research are students of a particular course and the videos are made for a specific didactic purpose. These students, courses, and educational settings differ, leading to inconclusive results on a larger scale and difficulties in generalising to further contexts. Thus, when using video tutorials, the didactic setting, participants, type and use of video tutorials must be considered. Further research considering these and additional factors is still necessary to piece together the complete puzzle; continued research that looks into various design factors and contexts is still needed. The current study aims to contribute to this developing field.

\section{Research context, method and data}

The five video tutorials analysed in this study were created as support for a total of 135 students in two courses:

- A first-semester academic writing course for part-time students, in which students write an academic literature review (55 students)

- A third-semester course in which students submit a research proposal during their semester abroad (80 students)

Both of these groups of students were enrolled on an International Management bachelor's degree program. The majority of students had previous work experience and were between 20 and 25 years of age (i.e. millennials or digital natives). The first-semester course took a blended-learning approach; classroom sessions took place every two to three weeks. Between the classroom sessions, students completed work on their own, such as searching for literature in academic databases, developing research questions, summarising, and paraphrasing. Although designed as supplementary material for these first and third-semester students, all but one task-specific video tutorial were made available to all our students on our university's YouTube channel. Links to these tutorials were placed on the class' online course platform (Moodle). In order to provide easy access for students, links were placed under the relevant session.

Based on our review of the literature, we set out to design a concept (presented at EATAW 2019). This concept included keeping our tutorials short (3-6 min), breaking them up into multiple short tutorials, where needed (Bowles-Terry et al., 2010; Chen \& Yang, 2019; Guo et al., 2014; Martin \& Martin, 2015), and focusing on the content to avoid any gimmicks (Buchner, 2018; Bowles-Terry et al., 2010; Ljubojevic et al., 2014). Although much of the video tutorials' content was based on aspects introduced in the classroom in previous versions of these courses, it was essential to create new sets of slides for the video tutorials. The information needed to be presented in a more condensed form. We created screencast tutorials to focus on the content rather than the lecturer or physical context (cf. taxonomy of styles in Chorianopoulos, 2018). Each tutorial had the same slide design to create recognisable consistency. They started with the same introduction and an outline of specific goals to help students assess whether the tutorial they are watching is the one they need. 
To better understand if and how these video tutorials provided support for the students' learning process and what the tutorials' strengths and weaknesses are, we took a dual approach. First, we assessed how our pilot tutorials on YouTube were used by analysing a user report compiled by YouTube Studio. Due to the limited viewership of these videos, relatively little information was provided by YouTube. The more views a video has, the more aspects they track. The YouTube report outlines viewership, including the date and number of views, as well as retention (i.e., when the viewers stopped viewing or scrolled to specific points in the video). Secondly, we distributed a survey to the students in both classes described above to gain insight into the perceived benefits to their learning process.

Of the 135 students who received the survey, 76 students took the survey (43 first-semester and 33 third-semester students). The number of responses to individual questions varied, as the respondents were not required to answer every question and could skip questions that were irrelevant to their experience. Following a series of multiple-choice and rating questions, the respondents were also given space to provide further comments.

The first questions in the survey were about students' general use of tutorials in order to understand their general preferences (see Figures 1 and 2). Figure 1 shows that around 50\% of the first and third semester students surveyed turned to video tutorials on a weekly or monthly basis. In contrast, $42 \%$ of the first-semester students and $36 \%$ of the third-semester students only rarely used video tutorials.

\section{Figure 1}

\section{Frequency of Students' Video Tutorial Use}

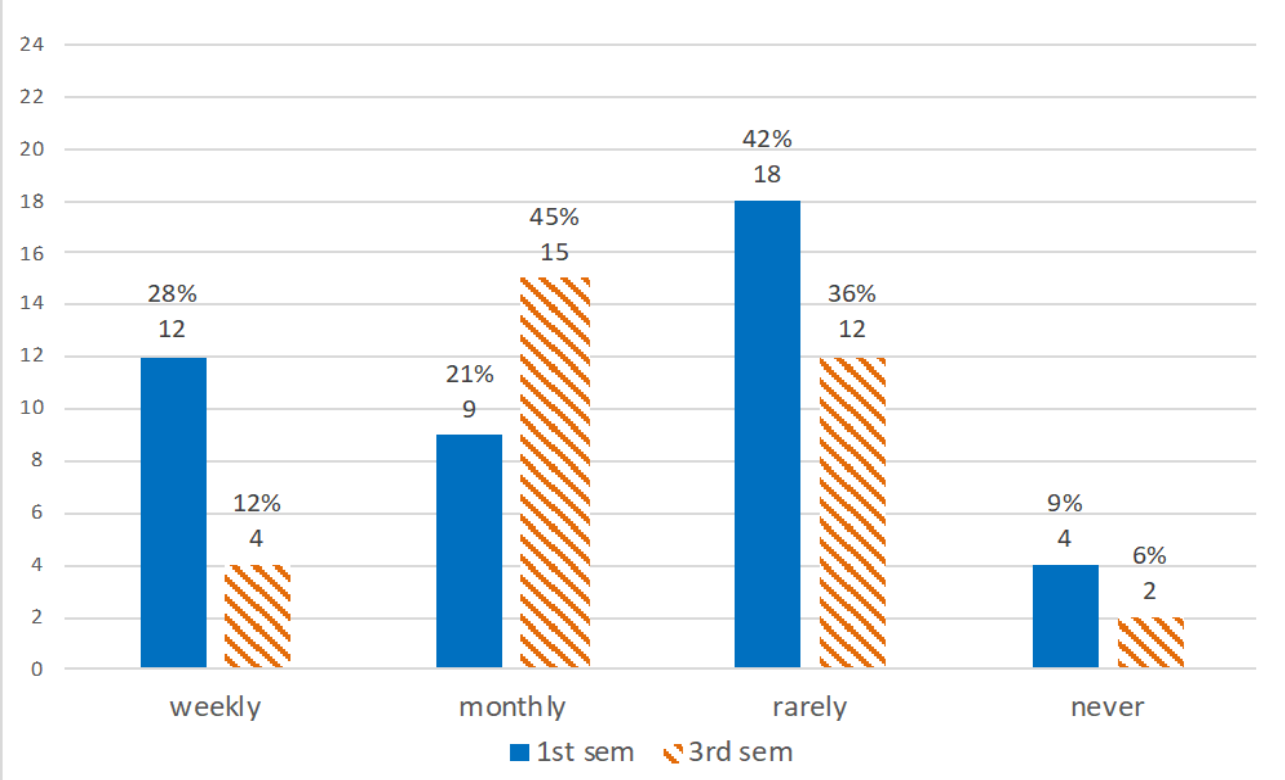

Note. The y-axis displays the number of responses in absolute numbers.

In addition to the frequency of video tutorial use, we were also interested in these students' preferred method of gaining additional course-related knowledge. Figure 2 illustrates two apparent differences in our first and third-semester students. $51 \%$ of first semester students showed preference for video tutorials compared to $39 \%$ of third semester students. $27 \%$ of third semester students preferred asking a lecturer compared to only $12 \%$ of first semester students. First semester students were also more likely to ask a classmate than the third-semester students. 


\section{Figure 2}

\section{Students' Preferred Method of Course Support}

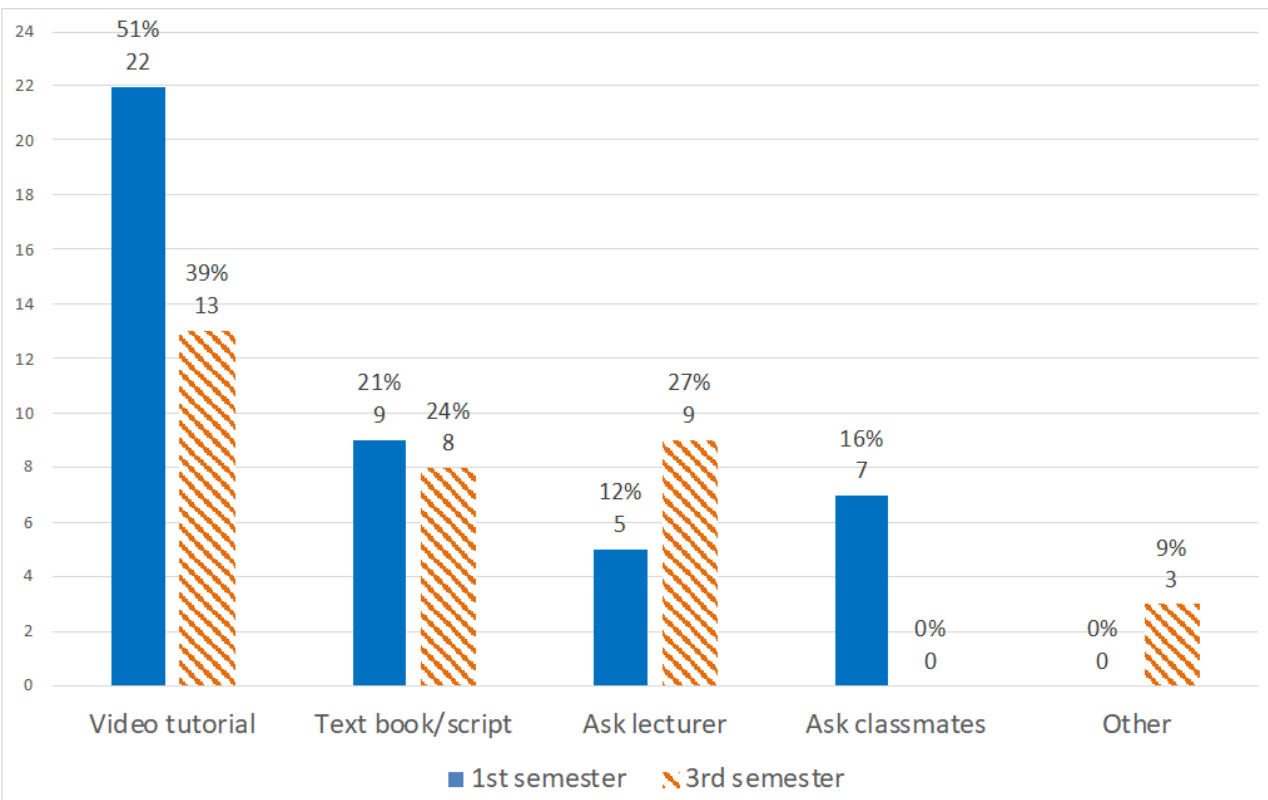

Note. The y-axis displays the number of responses in absolute numbers.

\section{Viewer Retention and Use}

To understand how viewers use these video tutorials, we have extracted aspects of the usage data from YouTube Studio. YouTube Studio allows owners of each video to retrieve data about how their videos are used, such as when the video is watched, how long viewers play the videos and when viewers scroll ahead to a later point in the video. Table 1 shows the video clip length, number of views and percentage of viewers who watched the entire tutorial. Although previous research indicates viewer retention is higher for shorter videos (Martin \& Martin, 2015), this is not the case here. The second to shortest video, Tutorial 4, was only viewed in its entirety by $41 \%$ of those who started it. In contrast, the longest videos, Tutorial 1 and 2 , were viewed in their entirety by $50 \%$ of those who started them. Therefore, length alone does not appear to be a deciding factor in viewer retention. Our results, do, however, confirm that lecturer intervention (e.g., information provided in class or via email) and connection to assignments play a large role in when the videos are viewed (Figure 3). The overall retention, shown in Table 1, of 41$50 \%$ speaks positively for the concept behind these tutorials and how they were implemented, as Martin and Martin (2015) found that only about a third of the viewers complete a whole video, regardless of various other factors. 
Table 1

YouTube Report Overview (18 November, 2019)

\begin{tabular}{|c|c|c|c|c|}
\hline & Video Title & Length & $\begin{array}{l}\text { Number of views } \\
\text { (18 November, 2019) }\end{array}$ & $\begin{array}{l}\text { Percentage of } \\
\text { viewers who } \\
\text { played the video } \\
\text { until the end }\end{array}$ \\
\hline Tutorial 1 & Assessing literature part 1 & $6: 37$ & 132 & Approx. 50\% \\
\hline Tutorial 2 & Assessing literature part 2 & $6: 09$ & 101 & Approx. 50\% \\
\hline Tutorial 3 & $\begin{array}{l}\text { Formulating a } \\
\text { research question }\end{array}$ & $3: 03$ & 35 & Approx. 50\% \\
\hline Tutorial 4 & $\begin{array}{l}\text { Characteristics of } \\
\text { a strong research question }\end{array}$ & $4: 48$ & 82 & Approx. 40\% \\
\hline Tutorial 5 & $\begin{array}{l}\text { Structuring a } \\
\text { research proposal }^{1}\end{array}$ & & $\begin{array}{l}\text { Not available on YouTube - } \\
\text { no data for these categories. }\end{array}$ & \\
\hline
\end{tabular}

Note. Link to tutorials:

https://www.youtube.com/playlist?list=PLagodZ7OfWso2BsX4Hmj7WkGfEOHNcs7T

The overview of viewership ${ }^{2}$ in Figure 3 shows when the tutorials were viewed. On 26 September, 2019, the first-semester students received their first assignment (due on 17 October, 2019) and were introduced to the tutorials. The assignment introduction and deadline appear to lead to the first two peaks in Figure 3.

\section{Figure 3}

Tutorial 1 - Viewership Dates

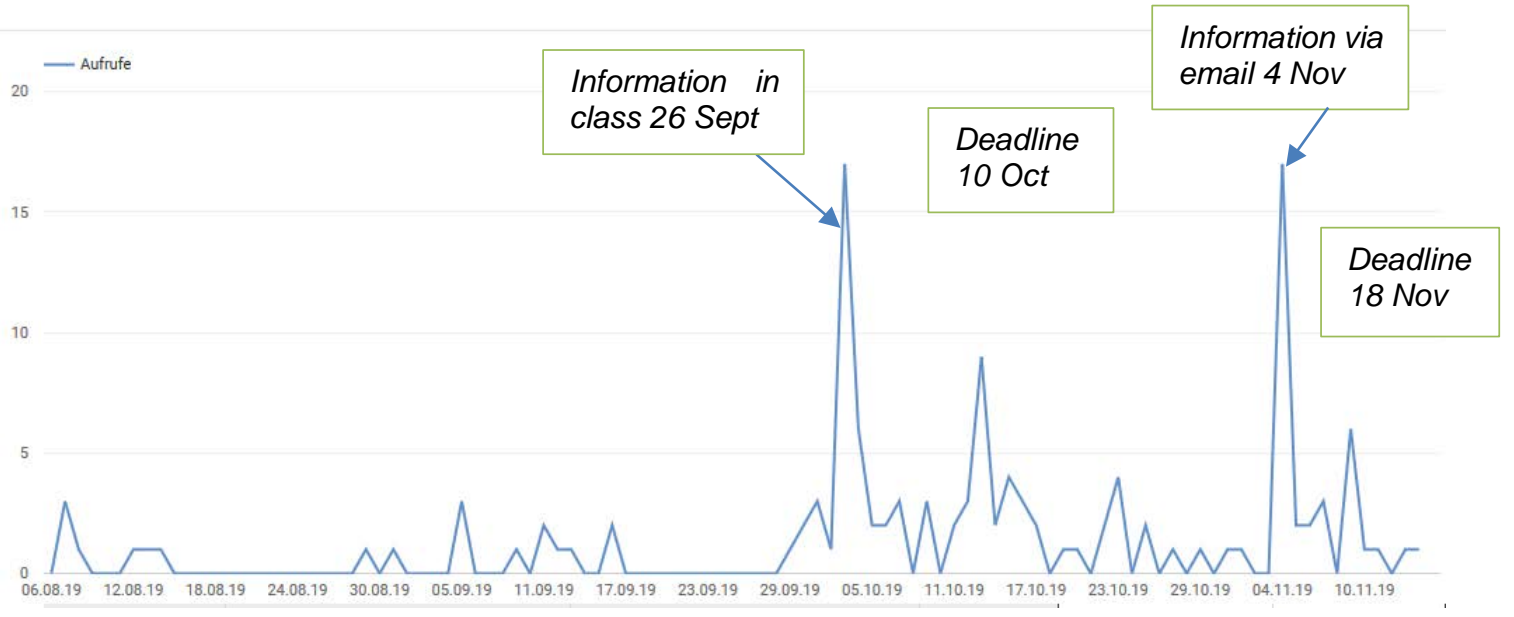

Note. The number of views is on the y-axis (YouTube Studio Channel Analytics as of 19 November, 2019).

\footnotetext{
${ }^{1}$ This tutorial was only made available to the $3^{\text {rd }}$ semester students. It was published on Moodle, the University's learning platform, not YouTube. It is included in this study as it was included in the survey.

2 Views and viewership are the terms used by YouTube Studio. Each time a video is played on YouTube for at least a couple of seconds counts as a view. We have taken on these terms. However, it must be noted that we did not use any eye-tracking or other technology, so we cannot guarantee how focused the individual views are.
} 
On 4 November, the third-semester students received further information about their assignment, via email, and links to the videos. This email, along with their deadline on 18 November, 2019, led to the third and fourth peaks.

Figure 3 only shows the views for one video tutorial, but our other video tutorials show similar peaks. These peaks show the direct connection between lecturer input - in class or via email - and approaching deadlines. Although these tutorials were online before the related assignments, and promoted by the university's social media team on Linkedln and Instagram at the end of August, most of the interest was only generated once these videos were linked to a course and an assignment, and promoted by the lecturer. The correlation between the lecturer's emails, the assignment deadline and peaks in Figure 3 support previous literature on the importance of convenience, accessibility and additional promotion (Bowles-Terry et al., 2010, p. 15; Weeks \& Davis, 2017), and the importance of the connection to the course and lecturer.

The YouTube Studio information on viewer retention provides information on which segments the students chose to watch. Although there is some individual variation between the four figures on retention (Figure 4-Figure 7), they point to a few consistent trends. The first trend seen in Figures 4-7 is that there is a considerable drop-off in the first $15-20 \mathrm{~s}$. This observation is consistent with previous literature that introductions are not considered to be of high importance (Bowles-Terry et al., 2010). In each of these videos, this was the time it took to introduce the topic and the specific goals of the video. Once this was complete, viewership leveled off. This initial drop in viewership leads to at least two potential conclusions: the goals did not match the viewers' expectations, or the introduction is too long. The retention figures (Figures 4-7) show evidence for both. The first conclusion is supported in that viewership drops off, whereas the second is supported by the fact that viewership increases slightly when the first complete content segment appears on the screen. This indicates that viewers scrolled to core content, skipping part of the introduction.

Figures 4-7 show $100 \%$ viewership at the beginning of each video and the percentage of viewers over the course of the video. The $x$-axis is the duration of the video in minutes and seconds (timeline). The $y$-axis shows the percentage of viewers. The small peaks and troughs illustrate at which point in the video viewers scrolled forward in the video (plunge) and when they let the video play (peaks). A drop in the line shows the moment on the video timeline when viewers scroll forward or discontinue watching it. A peak signifies the moment when viewers resumed normal viewing. Figures 4-7 are scaled according to the length of the video, so as not to misrepresent the slope of the curve.

\section{Figure 4}

Tutorial 1 Retention

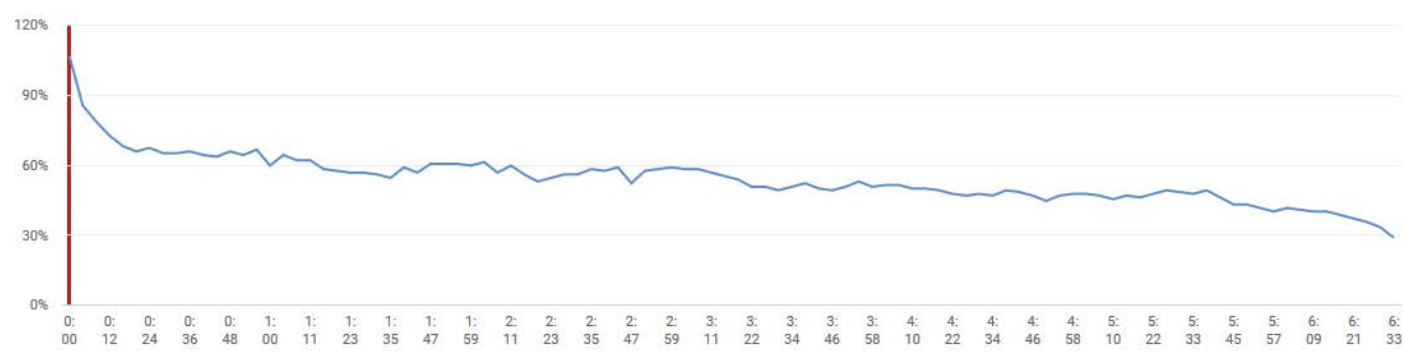

Note. Viewership of the video clip in minute and second intervals ${ }^{3}$ on $x$-axis, and drop in viewers on $y$ axis (YouTube Studio Video Analytics as of 19 November, 2019).

In the video-tutorial displayed in Figure 4, the main content begins at $24 \mathrm{~s}$ and viewership levels off at that point. Then up until approximately $3 \mathrm{~min}$, viewership is fairly stable despite a few

${ }^{3}$ We did not measure the click-rate but the more meaningful overview of viewer retention that is recorded by YouTube after a video is running for more than $2 \mathrm{~s}$, for Figures 4 and 5 . 
scrolls and skipped sections. There is a gradual decrease in viewership for 3 min until 5 min 37 $\mathrm{s}$, when the closing remarks begin and viewership falls more drastically.

\section{Figure 5}

Tutorials 2 Retention

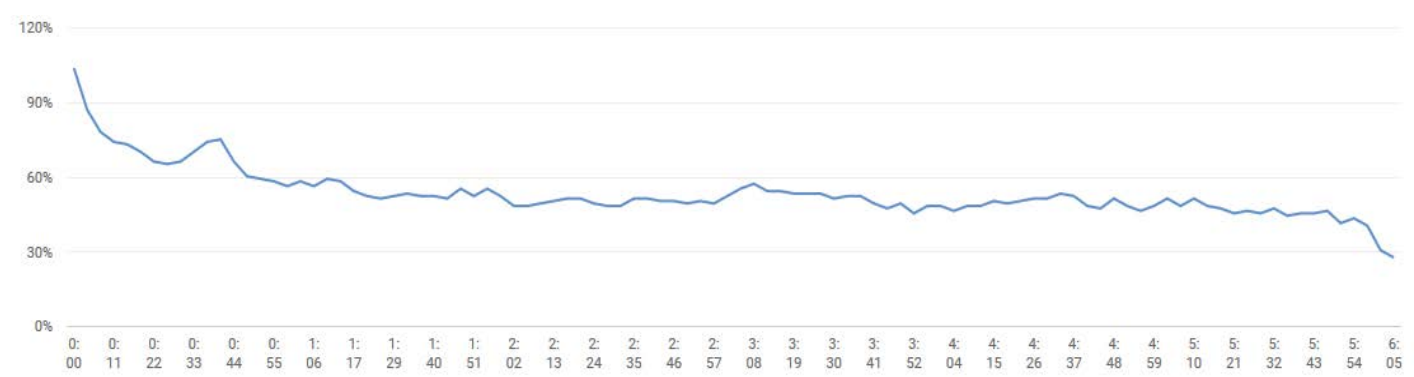

Note. Viewership of the video clip in minute and second intervals on $x$-axis, and drop in viewers on $y$-axis (YouTube Studio Video Analytics as of 19 November, 2019).

Viewer retention for the video-tutorial displayed in Figure 5 is similar to Figure 4, but shows slightly more pronounced peaks. As stated above, viewership falls quickly in the video's introduction providing support for Bowles-Terry et al's. (2010) finding that students are not interested in introductions. Viewership then increases again, at $22 \mathrm{~s}$, as soon as the visualisation of the main content begins. Then viewers scrolled until the time when the next visual is complete, at approximately $1 \mathrm{~min}$. The same pattern can be seen for the next two subtopic visuals, which are made completely visible at approximately $1 \mathrm{~min} 45 \mathrm{~s}$, and approximately $2 \mathrm{~min} 57 \mathrm{~s}$. This pattern of students scrolling to video-sections where new information is presented provides support for claims that material should be broken into chunks (Bowles-Terry et al., 2010), so that students can skip to what is most relevant to their needs. It also provides additional support for an inverted pyramid structure in which information most relevant to completing the task comes prior to more theoretical information which students generally consider to be less important (Bowles-Terry et al., 2010).

As the speaker explains the content in these tutorials, more visual support appears on the given slide. The phenomenon of scrolling to the complete visuals (see dips and peaks in Figures 47) appears to suggest that starting with visually complete slides may lead to greater viewerretention and more efficiency. This scrolling may also indicate that video tutorial content and structure should be presented differently than how it might be done in an interactive classroom. The evidence of viewers scrolling to complete visuals, shown in Figures 4-7, underscores the importance of considering the role and design of visual and oral input in video tutorials and contributes to research on how visual and audio information support each other (Mayer, 2001; Brame, 2016). However, the direct effects would have to be tested using video tutorials with similar audio and more static visuals that are complete from the beginning to the end of the audio support. 


\section{Figure 6}

Tutorial 4 Retention

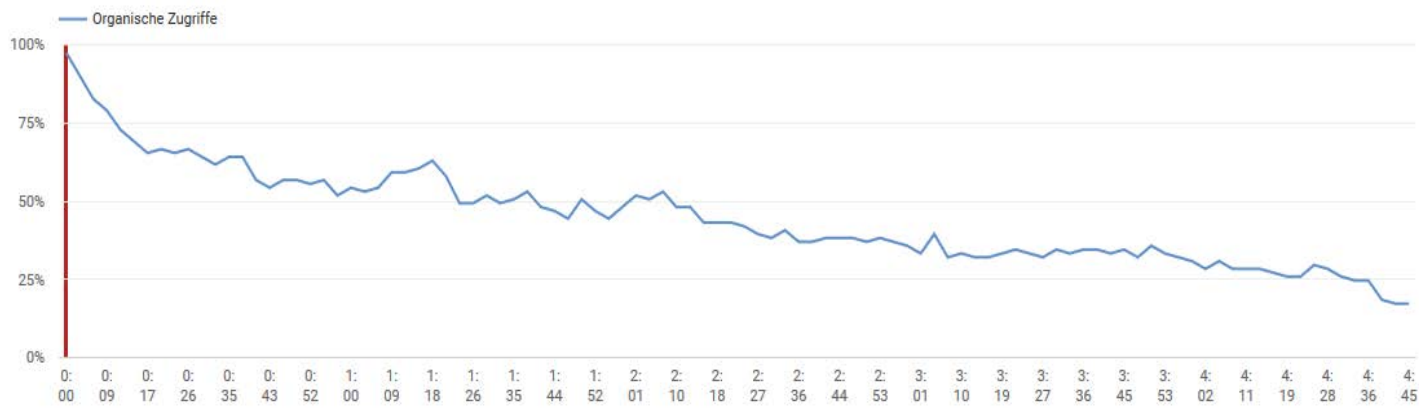

Note. Viewership of the video clip in minute and second intervals (YouTube Studio Video Analytics as of 19 November, 2019)

The retention overview in Figure 6 displays similarities to Figure 4 and Figure 5 in that viewership briefly levels off when the main content begins - after the initial drop during the introduction. At approximately $1 \mathrm{~min} 5 \mathrm{~s}$ the speaker begins orally and visually outlining the characteristics of a strong research question. At the 2 min mark, the visual and explanation are complete. From this point, a more consistent decline in viewership is seen. This 2 min mark is also the point at which the theoretical input is complete and the rest of the tutorial is devoted to the visualisation and discussion of concrete and practical examples.

\section{Figure 7}

Tutorial 3 Retention

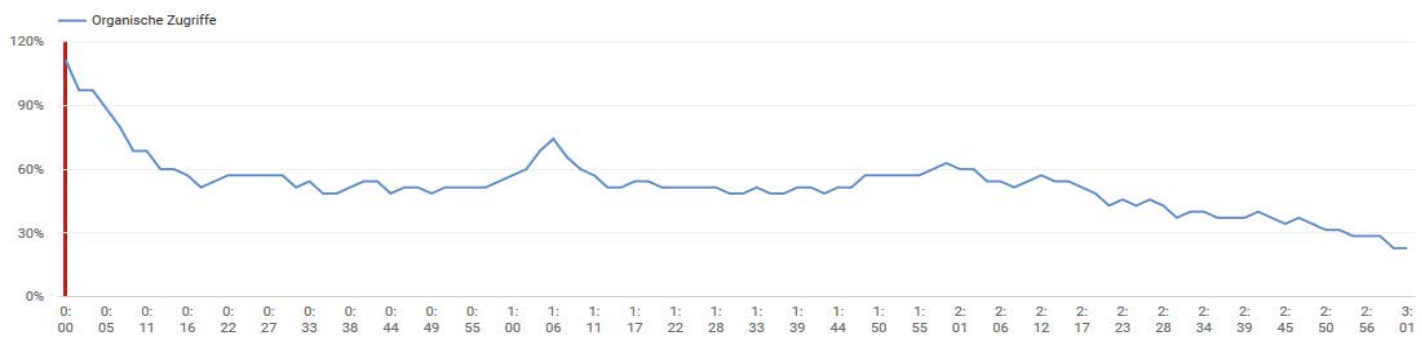

Note. Viewership of the video clip in minute and second intervals (YouTube Studio Video Analytics as of 19 November, 2019).

Figure 7 again shows how the viewers scrolled to the points when the visual support was complete. Between $55 \mathrm{~s}$ and $1 \mathrm{~min} 10 \mathrm{~s}$, the use of different interrogative pronouns for different types of research aims is explained and displayed, and at $1 \mathrm{~min} 44 \mathrm{~s}$ example questions are displayed. From 2 min $15 \mathrm{~s}$ on, tips for formulating good questions are provided. Figure 6 and Figure 7 both show a decline in viewership once the explanations of the topic and task are complete and examples begin, highlighting the importance of placing the most important information early. Additionally, when comparing Figure 4 and Figure 7, it is interesting to note that, despite Tutorial 1 (Figure 4), being more than twice as long as Tutorial 3 (Figure 7), viewer retention remains higher for longer tutorials (e.g. Tutorials 2 and 3). This indicates that length alone is not a deciding factor for viewership, but that other factors play a role. It also might suggest that examples are not desired in this form of media, which could be connected to the expectation that tutorials should be more procedural in nature (cf. Bowles-Terry et al., 2010). Further research might show that, for example, students expect video tutorials to help solve a problem quickly. 


\section{Perceived effects on learning}

In this survey, we aimed to gain insight into how our students value these video tutorials and their perceived impact on the learning process. 60 of the 76 respondents responded to a question about whether they felt supported by the video tutorials, shown in Figure 8. The majority of the respondents reported that they found the video tutorials very helpful, or to some extent helpful. More of the first semester students reported that they considered these video tutorials helpful. $22 \%$ of the third-semester students reported that the tutorials were not as helpful as they had hoped, whereas only one first semester student reported this. These results can perhaps be explained by the expertise reversal effect (Kalyuga, 2007), where more advanced learners perceived less benefit from video tutorials than novice learners.

\section{Figure 8}

First and Third-Semester Students' Perceptions of the Extent of Help Received

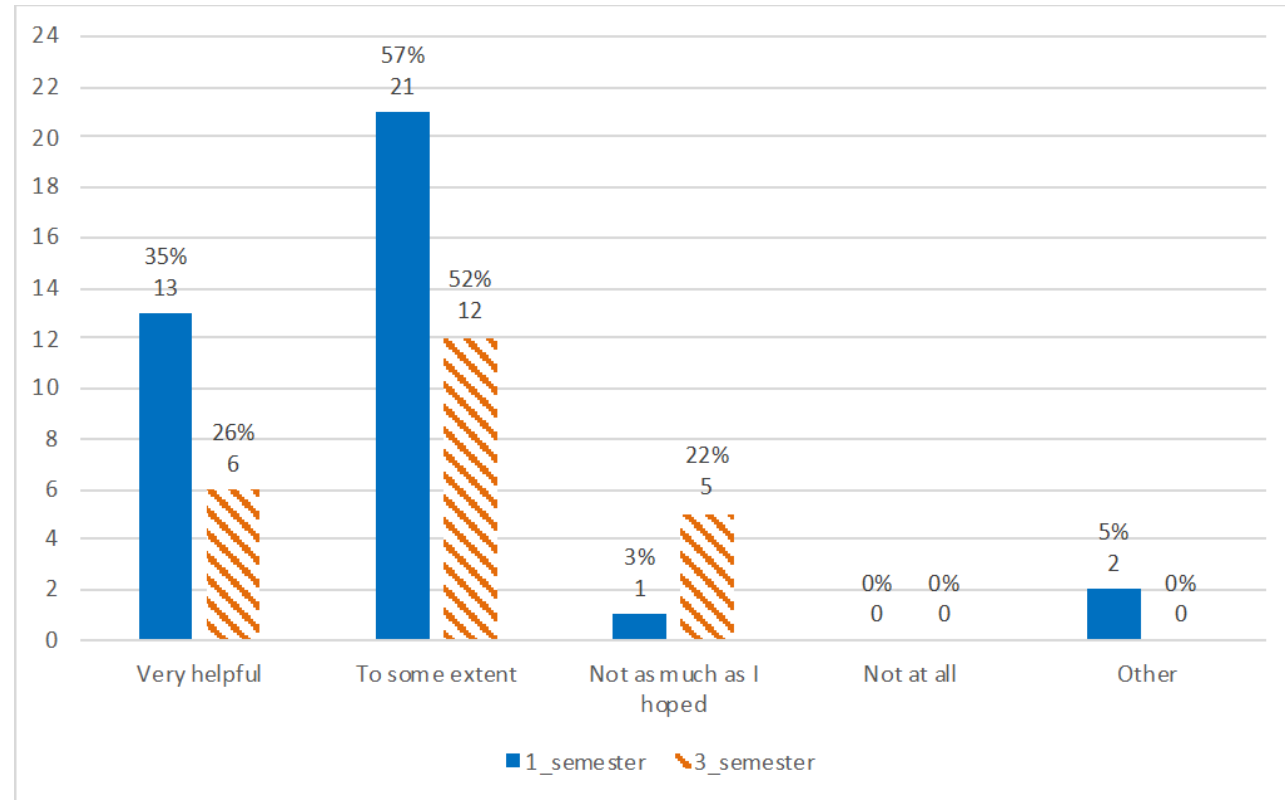

Note. The y-axis represents the number of student responses.

In order to understand if students found the tutorials helpful, we asked them to rank the tutorials in terms of how helpful they were in supporting their learning (see Figure 9 below). In this question, the survey respondents ordered the following aspects according to where they felt most supported: understanding of the topic, awareness of the task expectations, concrete tips to solve the task and confidence to tackle the task. In response to this question, students only indicated areas they perceived relevant, so the number of responses on each aspect in Figure 9 varies. Due to the small number of students, and the multiple categories, the first and thirdsemester students' responses were merged in Figure 9; however, a more detailed overview that distinguishes between the first and third-semester students can be found in the Appendix. 


\section{Figure 9}

\section{Level and type of support}

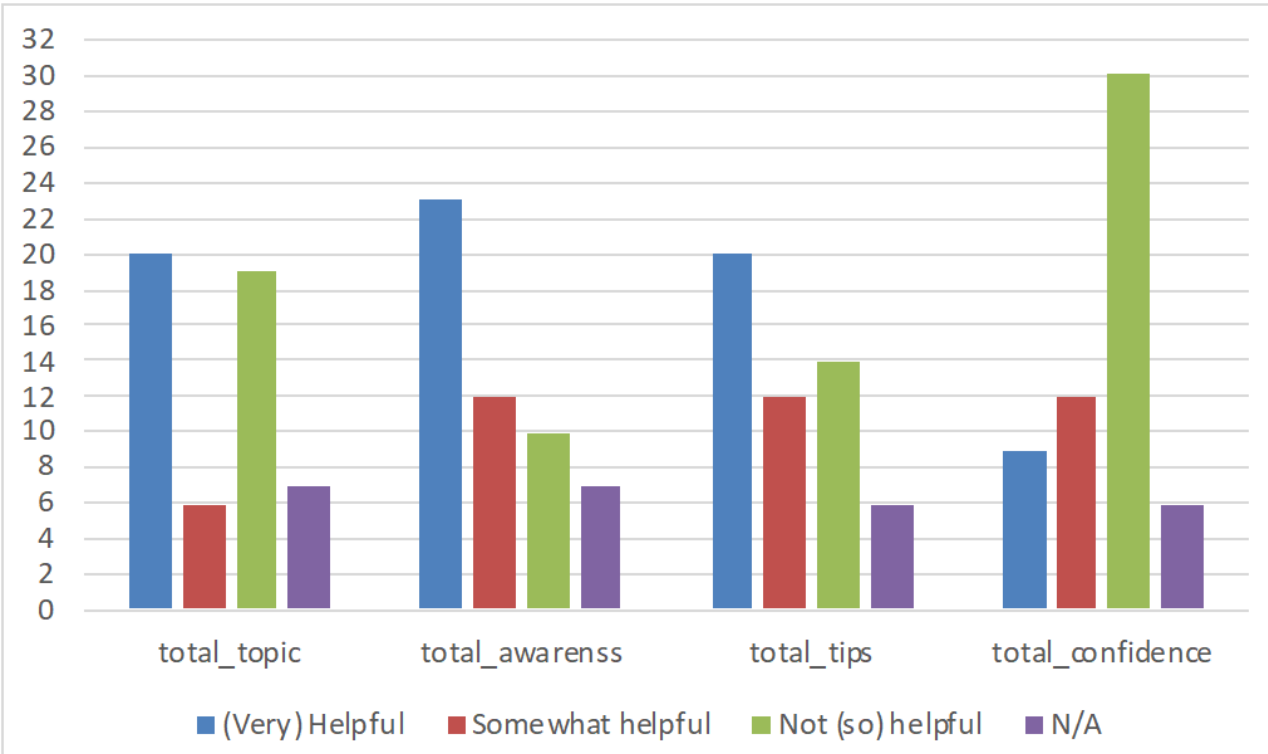

Note. Students were asked to rank the following aspects according to the level of support they received; the $y$-axis represents the number of students from both semester groups combined.

As can be seen in Figure 9, the majority of the respondents perceived a very helpful to somewhat helpful raised awareness of the task expectations. The majority also reported that they perceived the received tips to solve the task helpful, although the degree of support varied from somewhat to very helpful. This trend was stronger for the first-semester students (see Appendix). Figure 9 also indicates that these tutorials do not appear to have increased the majority's confidence in their ability. Again, here there was a slight difference, in that slightly more of the first-semester students perceived an increase in confidence. These results, similar to those in Figure 8, seem to indicate that the first-semester students perceived greater support from these tutorials, which would coincide with both Bussell et al. (2017) and Kalyuga's (2007) findings on the negative relationship between perceived video tutorial support and student level. However, a larger sample size would be needed to conduct the necessary statistical tests to confirm this. Figure 9 also shows a strong divide between students who considered the tutorials helpful in better understanding the topic. This divide, however, was seen in both semesters.

\section{Conclusion}

In this study, we set out to better understand which aspects of video tutorials, according to student perceptions, positively affect the learning process and how such tutorials should be adapted to be more effective.

Our students reported that they were better able to understand the assignment requirements and that they received concrete tips to complete a task. The survey results show that students find video tutorials helpful and would recommend them to others. Furthermore, we found that first-semester (novice) students perceived greater benefits from the tutorials than more advanced third-semester students. First-semester students were more likely to refer to tutorials, while third-semester students preferred to ask the lecturer for help. Thus, our study provides support for Bussell et al. (2017) and Kalyuga's (2007) finding that there is a negative relationship between perceived benefits from use of video tutorials and student level in relation to the content presented. This coincides with Lai et al. (2017) in that the usefulness of video tutorials is not universal, and it depends on a range of factors. 
This study contributes to the research on visual and audio use in video tutorials by Mayer (2001) and Brame (2016) and suggests that content which is most relevant for task completion should come first. Based on YouTube viewership data, the students appear to consider theory and examples less important than explanations of what they specifically have to do. This was observed by comparing what was happening in the videos at the time where viewership dipped and peaked. In Figures 6-7 viewership declined when examples were presented. This may also support the claim that millennials or digital native students favor task-based activities (Hawthorne, 2015). Further research into what aspects this generation of students most values would be an interesting focus for further research.

Findings indicate that the length of video tutorials is not as important for students as previous research indicates (cf. Bowles-Terry et al., 2010; Weeks \& Davis, 2017; Chen \& Yang, 2019; Guo et al., 2014). Students' use of video tutorials and their continued viewership suggest that additional factors are involved, as our two longest tutorials received the greatest viewer retention. Assignments appear to play a big role in viewership as viewership peaked as assignment deadlines approached. Lecturer input was more effective than promotion via social media in increasing tutorial viewership. While it is important to offer on-demand accessibility to videos, it is clear that students use such videos when the information need arises (cf. BowlesTerry et al., 2010; Weeks \& Davis, 2017).

While the literature highlights the need to state goals in video tutorials, our results indicate that students skip the introduction, which contains the learning goals. Instead, students scroll straight to the main content of the tutorials. Students also scrolled to get to the visually complete slides or content. This can indicate that students want to reduce the time spent on the activity e.g. by shortening the length of time it takes to complete the tutorial (Martin \& Martin, 2015). Nonetheless, goals can still be important as they can act as signposts to skip to the relevant content, giving support to chunking of the content of the video tutorials (Bowles-Terry et al., 2010). Thus, more research on the effects of the relationship between goals structure, content and length is still needed, and all of these factors need to be considered when creating tutorials.

While our research adds to the existing research on video tutorials, due to a small sample size and context-specific research setting, we cannot generalise beyond the current research context. However, the paper brings together a wide range of literature and provides new insights on the use and usefulness of video tutorials when teaching academic writing and research skills. There is clear evidence that students appreciate video tutorials. However, further research is needed regarding student expectations of video tutorials, the use of captions to perhaps allow for more efficient scrolling and information retrieval, and structure of content in video tutorials and instructional design/classroom instruction. Furthermore, future studies which examine the effects of video tutorials and student performance would provide additional support for the student perceptions documented here. This could include two cohorts of students, who receive video tutorials with similar content but different lengths or with different visualisation formats, to examine which factors have the greatest affect on student performance.

Much of the current research focuses on a very specific context, which makes comparison across contexts problematic. However, if consistency in goals, terminology and methods can be reached, interesting differences across specific contexts could be underscored.

\section{Acknowledgements}

We would like to express our gratitude to the EATAW 2019 participants who engaged in thought-provoking discussions and provided insightful feedback. We would also like to thank all the students who participated in our survey. 


\section{References}

Alekseiva-Petrova, A., Dorothee, A., \& Petrov, M. (2019). Experimental framework for evaluation of ICT impact on the learning process. International Journal of Education and Learning Systems, 4, 14-19.

Appleton, J. J., Christenson, S. L., Kim, D., \& Reschly, A. L. (2006). Measuring cognitive and psychological engagement: Validation of the student engagement instrument. Journal of School Psychology, 44(5), 427-445. https://doi.org/10.1016/j.jsp.2006.04.002

Balslev, T., de Grave, W., Muijtens, A., \& Scherpbier, A. (2005). Comparison of a text and video case in a postgraduate problem-based learning format. Medical Education, 39(11), 1086-92.

Bourdeau, D., Roberts, D., Wood, B., \& Korioth, J. (2017). A study of video-mediated opportunities for self-directed learning in required core curriculum. International Journal of Educational Methodology, 3(2), 85-91.

Bussell, H., Hagman, J., \& Guder, C. (2017). Research needs and learning format preferences of graduate students at a large public university: An exploratory study. College \& Research Libraries, 78(7), 978-998.

Bowles-Terry, M., Hensley, M. K., \& Hinchliffe, L. J. (2010). Best practices for online video tutorials in academic libraries: A study of student preferences and understanding. Communications in Information Literacy, 4(1), 17-28.

Brame, C. J. (2016). Effective educational videos: Principles and guidelines for maximizing student learning from video content. CBE-Life Sciences Education, 15(4), es6. https://doi.org/10.1187/cbe.16-03-0125

Buchner, J. (2018). How to create educational videos: From watching passively to learning actively. Open Online Journal for Research and Education, 12, 1-10.

Carson, E., \& Wilcox, R. (2019). Choosing wisely in pre-clinical medical education: A direct comparison of active learning methods for teaching metabolic liver disease. Medical Science Educator, 1-8.

Castro-Alonso, J. C., \& Sweller, J. (2019, July 24-28). The modality effect of cognitive load theory. [Conference presentation]. 10 $10^{\text {th }}$ International Conference on Applied Human Factors and Ergonomics (AHFE), Washington, DC, United States, http://drcriscastro.com/wp-content/uploads/2019/07/DrCrisCastro AHFE2019.pdf

Chen, C.-Y., \& Yang, Y.-H. (2018). Investigation of the effectiveness of common representational formats in online learner-paced software training materials. Innovations in Education and Teaching International, 57(1), 97-101. https://doi.org/10.1080/14703297.2018.1511443

Chorianopoulos, K. (2018). A Taxonomy of asynchronous instructional video styles. International Review of Research in Open and Distributed Learning, 19(1), 294-311.

DeVaney, T. A. (2009). Impact of video tutorials in an online educational statistics course. Journal of Online Learning and Teaching, 5(4), 600-608.

Engin, M. (2014). Extending the flipped classroom model: Developing second language writing skills through student-created digital videos. Journal of the Scholarship of Teaching and Learning, 14(5), 12-26.

Evmenova, A. S., Behrmann, M. M., Mastropieri, M. A., Baker, P. H., \& Graff, H. J. (2011). Effects of video adaptations on comprehension of students with intellectual and 
developmental disabilities. Journal of Special Education Technology, 26(2), 39-54. https://doi.org/10.1177/016264341102600203

Fredricks, J. A., \& McColskey, W. (2012). The measurement of student engagement: A comparative analysis of various methods and student self-report instruments. In S. L. Christenson, A. L. Reschly, \& C. Wylie (Eds.), Handbook of research on student engagement (pp. 763-782). https://doi.org/10.1007/978-1-4614-2018-7

Fulton, R., \& Fulton, D. (2018). Exploratory research on online learning in quantitative business disciplines. Development in business simulation and experiential learning, 45, 220-230.

Ganesan, N. (2018). Tools and techniques for the development of multimedia instructional modules. ACET Journal of Computer Education \& Research, 12(1), 1-24.

Galster, M., Mitrovic, A., \& Gordon, M. (2018, May 27-June 3). Toward enhancing the training of software engineering students and professionals using active video watching [Conference presentation]. 40 ${ }^{\text {th }}$ International Conference on Software Engineering: Software Engineering Education and Training, Gothenburg, Sweden.

Göldi, S., \& Künzi, S. (2017). Verbindlichkeit und effizienz durch echte kommunikation [Commitment and efficiency in real communication]. HR Performance, 1, 84-86.

Göldi, S. (2011). Von der Bloomschen Taxonomy zu aktuellen Bildungsstandards [From Bloom's taxonomy to current education standards]. Hep.

Guo, P., Kim, J., \& Rubin, R. (2014). How video production affects student engagement: An empirical study of MOOC videos. Proceedings of the first ACM conference on learning @ scale conference, 41-50.

Hawthorne, J. L. (2015, March). Engaging the skill set of the millennials: Librarians, content and technology in the mobile age. Proceedings of the Special Libraries AssociationArabian Gulf Chapter 21st Annual Conference 1. Hamad bin Khalifa University Press (HBKU Press).

He, Y., Swenson, S., \& Lents, N. (2012). Online video tutorials increase learning of difficult concepts in an undergraduate analytical chemistry course. Journal of Chemical Education, 89(9), 1128-1132. https://doi.org/10.1021/ed200685p

Henderson, M., Selwyn, N., \& Aston, R. (2017). What works and why? Student perceptions of 'useful' digital technology in university teaching and learning. Studies in Higher Education, 42(8), 1567-1579. https://doi.org/10.1080/03075079.2015.1007946

Hogarth, K., \& Luke, B. (2010, July 4-6). Transitioning from dependent to more independent learners: Using video tutorials as a means of helping students help themselves [Conference presentation]. 2010 AFAANZ Conference, Christchurch, New Zealand.

Hsiao, E., Mikolaj, P., \& Shih, Y. (2017). A design of scaffolding hybrid/online student-centered learning with multimedia. Journal of Educators Online, 14(1), 1-9.

Käfer, V., Kulesz, D., \& Wagner, S. (2017). What is the best way for developers to learn new software tools? An empirical compoarison between a text and a video tutorial.The Art, Science, and Engineering of Programming, 1(2). https://doi.org/10.22152/programming-iournal.org/2017/1/17

Kalyuga, S. (2007). Expertise reversal effect and its implication for its implications for learnertailored instruction. Educational Psychology Review, 19(4), 509-539. 
Korkut, S., Dornberger, R., Diwanji, P., Puthur, B., \& Märki, M. (2015). Success factors of online learning videos. International Journal of Interactive Mobile Technologies, 9(5), 17-22. https://doi.org/10.1109/IMCTL.2014.7011119

Lai, G., Zhu, Z., \& Williams, D. (2017). Enhance students' learning in business statistics class using video tutorials. Journal of Teaching and Learning with Technology, 6(1), 31-34.

Ljubojevic, M., Vaskovic, V., Stankovic, S., \& Vaskovic, J. (2014). Using supplementary video in multimedia instruction as a teaching tool to increase efficiency of learning and quality of experience. The International Review of Research in Open and Distributed Learning, 15(3), 275-291. https://doi.org/10.19173/irrodl.v15i3.1825

Martin, N., \& Martin, R. (2015). Would you watch it? Creating effective and engaging video tutorials. Journal of Library \& Information Services in Distance Learning, 9(1-2), 40-56. https://doi.org/10.1080/1533290X.2014.946345

Mayer, R. E. (2001). Multimedia learning. Cambridge University Press.

Mayer, R. E. (2005). Cognitive theory of multimedia learning. In R. E. Mayer (Ed.), The Cambridge handbook of multimedia learning (pp. 31-48). Cambridge: Cambridge University Press. https://doi.org/10.1017/CBO9780511816819.004

McGuinness, C., \& Fulton, C. (2019). Digital literacy in higher education: A case study of student engagement with e-tutorials using blended learning. Journal of Information Technology Education: Innovations in Practice, 18, 1-28. https://doi.org/10.28945/4190

Meij, H. \& Meij, J. (2014). A comparison of paper-based and video tutorials for software learning. Computer \& Education, 78, 150-159. https://doi.org/10.1016/j.compedu.2014.06.003

Mestre, L. (2012). Designing effective library tutorials. Woodhead.

Morton, D., \& Colbert-Getz, J. (2017). Measuring the impact of the flipped anatomy classroom: The importance of categorizing an assessment by Bloom's taxonomy. Anatomical Sciences Education, 10, 170-175. https://doi.org/10.1002/ase.1635

Paas, F., \& Ayres, P. (2014). Cognitive load theory: A broader view on the role of memory in learning and education. Educational Psychology Review, 26, 191-195.

https://doi.org/10.1007/s10648-014-9263-5

Plaga, C., Dettwiler, G., \& Stolle, D. (2019, April 18). Eine Reise in die Welt der Klicks, Likes und Herzchen: Zehn Social-Media-Nutzer erzählen von ihrer Leidenschaft [A journey into the world of clicks, likes and hearts: Ten social media users talk about their passion]. NZZ.

https://www.nzz.ch/feuilleton/medien/facebook-youtube-tiktok-instagram-co-10nutzer-erzaehlen-ld.1461283

Puma, S., Matton, N., Paubel, P. V., \& Tricot, A. (2018). Cognitive load theory and time considerations: Using the time-based resource sharing model. Educational Psychology Review, 30(3), 1199-1214. https://doi.org/10.1007/s10648-018-9438-6

Puma, S., \& Tricot, A. (2019). Cognitive Load theory and working memory models: Comings and goings. In S. Tindall-Ford, S. Agostinho, \& J. Sweller (Eds.), Advances in Cognitive Load Theory. Rethinking Teaching (pp. 41-52). Routledge.

Sachs, D., Langan, K., Leatherman, C., \& Walters, J. (2013). Assessing the effectiveness of online information literacy tutorials for millennial undergraduates. Journal College and undergraduate libraries, 20(3-4), 327-351.

https://doi.org/10.1080/10691316.2013.829365 
Statista (2020). Anzahl der monatlich eingeloggten Nutzer von YouTube weltweit in ausgewählten Jahren von 2013 bis 2020.

https://de.statista.com/statistik/daten/studie/718383/umfrage/anzahl-der-monatlicheingeloggten-nutzer-von-youtube-weltweit/

Stefanidis, D., Korndorffer, J., Heniford, T., \& Scott, D. (2007). Limited feedback and video tutorials optimize learning and resource utilization during laparoscopic simulator training. Surgery, 142(2), 202-206. https://doi.org/10.1016/i.surg.2007.03.009

Tewell, E. (2010). Video tutorials in academic art libraries: A content analysis and review. Journal of the Art Libraries Society of North America, 29(2), 53-61.

Thornton, D. E., \& Kaya, E. (2013). All the worldwide web's a stage: Improving students' information skills with dramatic video tutorials. In Aslib Proceedings, 65(1), 73-87. https://doi.org/10.1108/00012531311297195

Tsai, Y. (2019). Promotion of learner autonomy within the framework of a flipped EFL instructional model: perception and perspectives. Computer Assisted Language Learning, 1, 1-32. https://doi.org/10.1080/09588221.2019.1650779

Watzlawick, P., Beavin-Bavelas, J., \& Jackson, D. (1967). Pragmatics of human communication: A study of interactional patterns, pathologies and paradoxes. W.W. Norton.

Weeks, T., \& Davis, J. (2017). Evaluating best practices for video tutorials: A case study. Journal of Library \& Information Services in Distance Learning, 11(1-2), 183-195. https://doi.org/10.1080/1533290X.2016.1232048

Wells, J., Barry, R.M., \& Spence, A. (2012). Using video tutorials as a carrot-and-stick approach to learning. IEEE Transactions on Education, 55(4), 453-458. https://doi.org/10.1109/TE.2012.2187451

Worlitz, J., Stabler, A., \& Woll, R. (2018). The usage of video tutorials, personal support and written instructions for knowledge acquisition and refreshment. Quality Innovation Prosperity, 22(2), 128-138. https://doi.org/10.12776/qip.v22i2.1065

YouTube Studio (2019). Zentrum Schreiben Tutorials Video Analytics [Data set]. https://www.studio.youtube.com 


\section{Appendix}

\section{Table A1}

Level and Type of Support by Semester

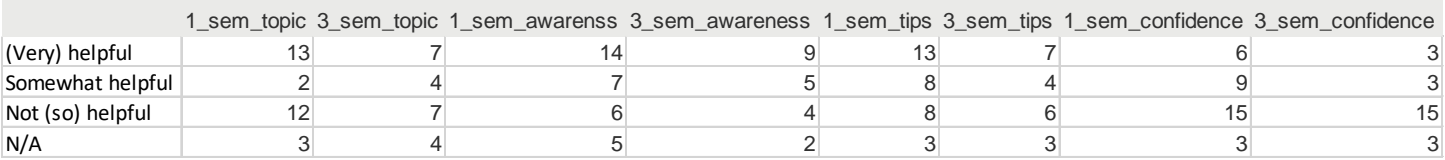

Note. Raw data separating responses from first semester and third semester students. 